\title{
Rosas y el rosismo: lecturas sobre la república plebiscitaria ${ }^{1}$
}

\section{Rosas and rosismo: readings on the plebiscitary republic}

\author{
Marcela Ternavasio ${ }^{2}$
}

\section{Resumen}

El presente ensayo reflexiona sobre la compleja relación, histórica e historiográfica, entre Rosas y el rosismo y se ocupa de analizar ciertos problemas y puntos ciegos que presentó el experimento de una república plebiscitaria en Buenos Aires en la primera mitad del siglo XIX y las derivaciones que dejó proyectadas en las posteriores interpretaciones. El objetivo es recuperar algunos debates que abrió el enorme avance del campo disciplinar sobre el tema en las últimas tres décadas y discutir enfoques que ponen en juego las relaciones entre política y memoria, sociedad y estado, discurso y realidad, individuo y contexto. Los argumentos se ordenan en torno a una pregunta central: ¿qué dilemas sigue planteando en la historigrafía más renovada la interpretación de un período controversial y a la vez dominado por un líder político cuyo nombre propio marcó toda una época?

Palabras clave: Rosas - Rosismo - República - Plebiscito - Voluntad

\begin{abstract}
:
This essay reflects on the complex relationship, historical and historiographical, between Rosas and Rosismo and deals with certain problems and blind spots that the experiment of a plebiscitary republic in Buenos Aires presented in the first half of the 19th century and its derivations in the later interpretations. The objective is to recover some debates that the great advance of the disciplinary field on the subject opened in the last three decades and to discuss approaches that put into play the relations between politics and memory, society and state, discourse and reality, individual and context. The arguments are arranged around a central question: what dilemmas does the interpretation of a controversial period dominated by a political leader whose proper name marked an entire era still pose?
\end{abstract}

Keywords: Rosas - Rosismo - Republic Plebiscite - Voluntary

\footnotetext{
${ }^{1}$ Trabajo recibido el 10/09/2020. Aceptado el 13/11/2020.

${ }^{2}$ Universidad Nacional de Rosario. Consejo Nacional de Investigaciones Científicas y Técnicas. Contacto: marcelaternavasio@gmail.com
} 


\section{Introducción}

El primer bosquejo biográfico que Stendhal escribió de Napoleón Bonaparte, inconcluso y editado parcialmente a fines del siglo XIX, se presentaba como una réplica al libro de Madame de Staël -Considérations sur les principaux événements de la Révolution française- publicado en 1818: el «libelo lo lanza el primer talento del siglo contra un hombre que, desde hace cuatro años, es objeto de venganza de todos los poderes de la tierra» (Stendhal, 2007, p. 43). En su Vida de Napoleón hacía confluir la admiración que mantenía hacia su biografiado -aquel general republicano que había salvado la revolución- con una crítica a las derivas del personaje una vez convertido en cónsul vitalicio y luego en emperador, ratificado en ambas ocasiones por un plebiscito popular: el «Cromwell de la Revolución», que «imbuido de ideas romanas» podría haber establecido la república, terminó deslumbrado por una corona ante sus ojos y por la ambición de «fundar una dinastía de reyes» de la Casa de Bonaparte (Stendhal, 2007, p. 78).

Casi dos décadas después, el autor de Rojo y Negro retomó su viejo proyecto en Memorias sobre Napoleón, también inconclusas, cuando habían pasado quince años de la muerte del corso y las imágenes sobre el personaje se habían multiplicado, ya sea para condenarlo, justificarlo o exaltarlo a través del mito del héroe. Esa imágenes enfrentaron un nuevo desafío al regresar la historia «como farsa», según la frase que consagró Karl Marx en El Dieciocho Brumario, cuando Luis Bonaparte fue consagrado presidente de la Segunda República a través del sufragio universal y proclamado emperador tres años después refrendado por un plebiscito. Marx (1973) evocaba allí la memoria histórica para afirmar que «los franceses, mientras estaban en revolución, no podían sobreponerse al recuerdo napoleónico» y que «ante los peligros de la revolución se sintieron atraídos por el recuerdo de las ollas de Egipto» hasta obtener «no sólo la caricatura del viejo Napoleón, sino al propio viejo Napoleón en caricatura» (p.18).

Las obras citadas -producidas desde coyunturas, géneros, objetivos y perspectivas muy diferentes- formaron parte de las múltiples escrituras que merecieron los dos Bonaparte. Como suele ocurrir con los personajes que asumen una centralidad insoslayable en el curso de la historia, esas escrituras despliegan interpretaciones divergentes y abren querellas que acompañan los climas de época. Los ejemplos sobran para mostrar las variantes que pueden adoptar las versiones sobre un período 
histórico marcado a fuego por un hombre o una mujer que arriban a las más altas posiciones de poder político. Y entre esos ejemplos, el caso que me ocupa en este ensayo -Juan Manuel de Rosas y el rosismo- es uno más, aunque cabe destacar que para la historia argentina del siglo XIX es el caso, como lo es para el siglo XX el de Juan Domingo Perón y el peronismo. Ambos, además de representar identidades políticas que dividieron a la sociedad y a sus posteriores intérpretes en admiradores y detractores, exhiben la dificultad de conjugar la dimensión individual y colectiva del fenómeno que condensan a la hora de abordarlos historiográficamente.

El papel que Rosas desempeñó en la historia rioplatense es un tema de debate abierto que en algunos sentidos puede compararse salvando las distancias y diferencias de escala- con el de los Bonaparte luego de las dos grandes revoluciones ocurridas en Francia. La versión criolla que vino a poner «fin a la revolución, principio al orden» se plasmó en una fórmula que, con sus rasgos idiosincráticos, combinó principios y mecanismos utilizados por quienes terminaron coronándose como emperadores: sobre la base de la soberanía popular refrendada por el dispositivo plebiscitario se creó una autoridad unipersonal con sumos poderes. Por supuesto que el uso de dicho dispositivo varió en cada uno de los casos. No es mi intención delinear forzadas analogías, ni dar cuenta de las particulares circuntancias de los dos momentos bonapartistas entre los cuales se ubica el momento rosista, sino reparar en el origen de un repertorio político. En este sentido, Stendhal y Marx expresaban, al calor de los acontecimientos, la perplejidad y desilusión frente a un rumbo histórico que presentaba una gran paradoja: el pueblo como protagonista de una inédita experiencia republicana terminó empoderando a un personaje y elevándolo a una posición política también inédita. Similar perplejidad exhibieron los actores contemporáneos a Rosas y quienes después de su caída se vieron enfrentados a interpretar ese pasado, trazándose de allí en más diversos vínculos entre historia, memoria y política.

En las siguientes páginas me propongo regresar sobre la compleja relación -histórica e historiográfica- entre Rosas y el rosismo, con el objeto de reflexionar sobre ciertos aspectos y puntos ciegos que presentó el experimento de una república plebiscitaria en la Buenos Aires de la primera mitad del siglo XIX y las derivaciones que dejó proyectadas en las posteriores interpretaciones. Para abordarlos me centraré en algunos debates que en las últimas tres décadas abrió el enorme avance del cam- 
po disciplinar sobre el tema. El lector no encontrará aquí un estado de la cuestión sino un intento de reubicar problemas y discutir enfoques que ponen en juego los vínculos entre política y memoria, sociedad y estado, discurso y realidad, individuo y contexto. Problemas y enfoques que se ordenan en torno a un interrogante: ¿qué dilemas sigue planteando en la historigrafía más renovada la interpretación de un período controversial y a la vez dominado por un líder político cuyo nombre propio marcó toda una época?

\section{El dilema de la responsabilidad política}

En un agudo análisis sobre el origen de una narrativa histórica acerca del rosismo, Alejandro Eujanian (2015) explora los debates desarrollados en Buenos Aires en la década de 1850 y los problemas que enfrentaron los actores que comenzaron a modelar las interpretaciones sobre el pasado reciente. En aquella coyuntura, en la que no existía nada parecido a un campo de historiadores profesionales, las preguntas en torno a cómo dosificar la memoria y el olvido, cómo pacificar y reconciliar a una sociedad profundamente dividida, cómo tramitar las heridas del pasado, y cómo consagrar un relato para las generaciones futuras que condenara las atrocidades cometidas por el tirano, estuvieron en el centro de la escena. Cuestiones todas que Eujanian indaga con extrema sutileza analítica, exhibiendo problemáticas que no son ajenas a las que desafían a los historiadores actuales dedicados a la llamada «historia reciente». Las formas de denominar el crimen estatal y el régimen autoritario, o los criterios para establecer las complicidades y responsabilidades del estado y de la sociedad, estuvieron presentes en la agenda de los hombres y mujeres encargados de elaborar los primeros relatos sobre el rosismo a mediados del siglo XIX, como están en la agenda de quienes estudian los hechos de violencia producidos en los años más oscuros del siglo XX en Argentina. En ambos casos se dirimieron y dirimen asuntos que afectan a toda la ciudadanía, y en ambos casos se abrieron coros de voces con posiciones diversas que, como demuestra Marina Franco (2018) en un reciente estado de la cuestión sobre los estudios en torno a la última dictadura militar, revelan la superposición y tensión entre los campos político, jurídico, intelectual y académico.

De los diferentes registros que Eujanian recorre en El pasado en el péndulo de la política, hay un aspecto que desarrolla en detalle: el debate 
surgido en la legislatura de Buenos Aires acerca de la responsabilidad política, cuando se somete a deliberación el juicio a Juan Manuel de Rosas. Dicho debate, además de discurrir sobre el tipo de juicio que debía llevarse adelante y la forma de definir los delitos y crímenes perpetrados, desnudaba un problema de fondo de compleja resolución. Si tales delitos se habían cometido bajo el pleno uso de las facultades extraordinarias y la suma del poder público, la pregunta central era la cuota de responsabilidad que le cabía a la Sala de Representantes que se las había delegado al titular del Ejecutivo de la provincia de Buenos Aires. Por cierto que no era la primera vez que, después de la Revolución de Mayo, se sometía a juicio a miembros de gobiernos caídos en desgracia ni era nuevo el otorgamiento de poderes de excepción. Pero sí era la primera vez que su uso se prolongó por tanto tiempo en el marco de un sofisticado sistema que apuntó a dotar a Rosas de una legitimidad unanimista ritualizada a través del culto a su persona.

El alcance de la responsabilidad legislativa comprometía a parte de la dirigencia política que había actuado en la Sala rosista y continuaba formando parte -no sin tensiones- del elenco gobernante que tomó el relevo en Buenos Aires después de Caseros. No obstante, el punto tal vez más conflictivo era el eslabonamiento hacia abajo del argumento esgrimido: las sucesivas legislaturas habían sido electas por sufragio universal masculino, y por lo tanto sus diputados hablaban y decidían en representación del pueblo. El juicio ejemplar a la persona de Rosas, cuyo fallo, como afirma Eujanian (2015), estaba destinado a «blindar la interpretación que las generaciones futuras debían realizar sobre este período» (p. 289), ponía en evidencia el engranaje en el que se había montado su autoridad y la borrosa frontera trazada en la cadena de complicidades.

Esa borrosa frontera ya había sido advertida por los propios diputados del sector del partido federal reticente a renovar las facultades extraordinarias al Ejecutivo durante el primer gobierno rosista (18291832). Algunos miembros de ese grupo se preguntaban, justamente, cuál sería el grado de responsabilidad que les competía como representantes de la soberanía popular en el uso de los poderes de excepción y cuál sería «el tercero en esta discordia» para «conocer» y «juzgar» en el asunto, frente a un contexto político que carecía de una constitución ${ }^{3}$. Tal

${ }^{3}$ Diario de Sesiones de la Honorable Junta de Representantes de Buenos Aires, sesión n ${ }^{\circ}$ 204, 30 de julio de 1830, p. 15. 
advertencia derivó en el rechazo a conceder dichos poderes para un nuevo mandato del gobernador y en la renuncia de Rosas a continuar ocupando el cargo. Pero el tema se convirtió en foco de debate de la legislatura de 1833, dominada por los federales cismáticos, dispuestos a evitar un avance del sector leal a Rosas. Como ha demostrado recientemente Cecilia Bari (2020), en aquel año crucial se jugó una alternativa política surgida dentro del federalismo más inclinado a respetar los principios liberales. Los cismáticos impulsaron la sanción de una constitución provincial que ponía fuertes límites al Ejecutivo y prohibía explícitamente que el Legislativo le delegara poderes extraordinarios. La iniciativa fracasó en el marco de una intensa conflictividad entre los dos sectores federales, y encontró su punto de inflexión en la Revolución de los Restauradores promovida por los apostólicos rosistas.

La correlación de fuerzas había cambiado y Rosas supo capitalizar aquel ambiente político y el aprendizaje que le dejaba el pasado reciente. A partir de 1835, una vez que regresó a la primera magistratura de la provincia, la movilización popular, aunque fuera en su apoyo, debía estar fuertemente controlada, como asimismo la aritmética de los votos que otorgaba mayoría en la legislatura. De allí en más, la voluntad de imponer la lista única de candidatos y la celebración de plebiscitos y consultas populares habilitaron a Rosas a salir del laberinto por arriba. A través de ambos mecanismos, el gobernador exhibió la ansiada unanimidad electoral y neutralizó la profunda desconfianza que le generaba la deliberación legislativa, refrendando la entrega de la suma del poder público a través de plebiscitos. En nombre de una voluntad general que no admitía mediaciones, el gobernador logró domesticar, finalmente, el escenario político, y condenar al espacio de la clandestinidad cualquier atisbo de oposición al régimen que encarnaba (Ternavasio, 2002).

El dilema en el juicio a Rosas era, entonces, cómo codificar los excesos a los que podía conducir el ejercicio de la soberanía popular; un tópico que, desde Benjamin Constant en adelante, se convirtió en un clásico para la tradición liberal. La manera de salvar esta dificultad a la hora de establecer la culpabilidad y el castigo de los delitos cometidos fue reafirmar que, durante los gobiernos del Restaurador de las Leyes, el pueblo carecía de libertad para hacer uso de los atributos de la soberanía popular. El argumento, sin embargo, dejaba pendiente el fantasma que Domingo F. Sarmiento supo reconocer poco después de la caída de su gran enemigo político: 
Rosas era un republica-no que ponía en juego todos los artificios del sistema popular representativo. Era la expresión de la voluntad del pueblo, y en verdad que las actas de elección así lo muestran. Esto será un misterio que aclararán me-jores y más imparciales estudios que los que hasta hoy hemos hecho ${ }^{4}$.

En efecto, el misterio al que aludía Sarmiento remitía a la singularidad de un liderazgo político de base popular montado sobre discursos, rituales y dispositivos institucionales republicanos que sustentaron un poder extremadamente autoritario. El problema se proyectó como una sombra en las interpretaciones posteriores y no pudo clausurarse con la «operación de memoria» que, según concluye Eujanian (2015), abarcó la década de 1850 imponiendo una solución transaccional entre aquello que debía ser recordado y lo que era preferible olvidar. Con esa operación se procuraban diluir las inevitables cadenas de complicidades que involucraban ya no sólo a una parte de las altas dirigencias sino a toda la sociedad bonaerense que había acompañado el experimento rosista.

Sobre esa sombra se reeditaron, una y otra vez, las batallas por la historia y se fueron superponiendo capas de memorias y olvidos que contribuyeron a reactualizar la figura de Rosas toda vez que resultó funcional al combate por el pasado y a las disputas políticas por el presente. Pero más allá de los variopintos usos políticos del rosismo desplegados desde el siglo XIX hasta nuestros días, me interesa reflexionar sobre la cuestión que quedó flotando en el juicio: el papel atribuido al propio Rosas y a la sociedad que lo elevó al lugar de excepción que supo ocupar y mantener.

\section{Entre la sociedad, el estado y el liderazgo político}

Es bien conocida la frase con la que Tulio Halperin Donghi cerró su influyente libro Revolución y guerra (1972): «Tal como entrevió Sarmiento, la Argentina rosista, con sus brutales simplificaciones políticas, reflejo de la brutal simplificación que independencia, guerra y apertura al mercado mundial habían impuesto a la sociedad rioplatense, era la hija legítima de la revolución de 1810» (p. 404). Citada una y otra vez por los especialistas en el temprano siglo XIX, la frase condensaba una

${ }^{4}$ Citado en Adolfo Saldías, «El Gobierno de Rosas», Biblioteca Internacional de Obras Famosas, Buenos Aires y Londres, 1910, pp. 9173-9174. 
perspectiva e iluminaba una agenda historiográfica. Las investigaciones que tomaron impulso sobre el período rosista a partir de las décadas de 1980 y 1990 se nutrieron de -y dialogaron con- la obra de Halperin desde diversos campos, temáticas y enfoques. En ese renovado clima académico se dejaban atrás las polémicas montadas en matrices políticoideológicas, más interesadas en posicionarse sobre el presente que en investigar el pasado, y surgían otras nuevas. En estas últimas me centraré a continuación, a partir de los debates que suscitaron algunas obras emblemáticas, publicados en revistas científicas, con el objeto de trazar ciertos nudos problemáticos vinculados al interrogante que ordena estas reflexiones.

En primer lugar, es oportuno recuperar los recientes intercambios en torno a la edición en español de Paisanos itinerantes de Ricardo Salvatore (2018), publicado en inglés tres lustros antes. Los comentarios que el libro ha merecido de Beatriz Bragoni, Melina Yangilevich, Geraldine Davies, Judith Faberman y Roy Hora, además de destacar el carácter pionero de una investigación abocada a mostrar la experiencia de los sectores subalternos en la Buenos Aires rosista, son una buena muestra de los avances producidos hasta el presente y del peso que han tenido los enfoques centrados en la sociedad y el estado ${ }^{5}$. Respecto de la sociedad, hoy contamos con un mapa social de la provincia de Buenos Aires mucho más completo y sofisticado que el que poseíamos no hace tanto tiempo. A la confección de ese mapa contribuyeron los trabajos dedicados a explorar los sectores subalternos rurales y urbanos, los segmentos medios de la sociedad, y los que discuten el perfil de los terratenientes. Algo parecido aplica a los estudios sobre los agentes y recursos estatales, gracias a las pesquisas en torno al rol de los ejércitos y milicias, jueces de paz y policía en el entramado del poder rosista.

En el marco de estos aportes, los comentarios referidos a Paisanos itinerantes reflejan una variedad de matices acerca de cómo interpretar los vínculos entre actores sociales y agentes estatales. Por un lado, se discute la capacidad de «agencia» de los diversos segmentos sociales -especialmente de los sectores populares- para defender sus derechos e

\footnotetext{
${ }^{5}$ Véanse las intervenciones de Beatriz Bragoni, Melina Yangilevich y Ricardo Salvatore, en «Paisanos itinerantes. Un balance historiográfico a dieciséis años de su primera edición en inglés», Revista Electrónica de Fuentes y Archivos (REFA), n 10, 2019, pp. 211-254. Las intervenciones de Geraldine Davies Lenoble, Judith Faberman, Roy Hora y Ricardo Salvatore, en «Notas y debates», Boletín del Instituto de Historia Argentina y Americana Dr. Emilio Ravignani, $\mathrm{n}^{\circ}$ 52, 2020, pp. 116-165.
} 
intereses frente al orden que el rosismo procuró imponer; los niveles y esferas de resistencia y negociación frente al mercado y el estado; y la periodización y espacialización que trazaron esas prácticas desde el primer rosismo hasta el más maduro y rutinizado. Por otro lado, se debate si para este período es pertinente utilizar la categoría «estado» entendido como separado de la sociedad civil; si la red de agentes en las que se montó la autoridad podían distinguirse de la misma sociedad en la que actuaban; y cuánta eficacia exhibió esa red para disciplinar a la sociedad y establecer un sistema de coacción y control a lo largo y a lo ancho de aquella provincia en constante expansión territorial.

Paralelamente a estas líneas de indagación se fueron desarrollando otras que profundizaron en la clave republicana del régimen a través del análisis de los discursos (Myers, 1995), la sociabilidad (González Bernaldo, 2001), las fiestas y rituales (Salvatore, 1998; Munilla Lacasa, 2013), o las elecciones (Ternavasio, 2002). Aquí también los debates se hicieron presentes y, en algunos casos, expresaron las tensiones entre el campo de la historia social y el de la historia intelectual y política. Un temprano ejemplo de estas disonancias se observa en el comentario que publicó Juan Carlos Garavaglia al libro de Jorge Myers (1995), Orden y Virtud, una obra pionera en el estudio del discurso publicístico del rosismo que postula la hipótesis de una matriz republicana-clásica expresada, entre otros topos, en el «agrarismo republicano» que moduló parte de ese discurso. Esta referencia fue el foco de las objeciones de Garavaglia, quien cuestionó la tendencia a privilegiar el análisis del discurso por sobre el «contexto referencial» en el que se inscribía. Un contexto que, en este caso, remitía a la historia agraria de la que el comentarista fue un gran exponente. Myers, en su respuesta, ponía de relieve los riesgos teóricos y metodológicos de recrear un sistema de jerarquización de los distintos campos del saber histórico y afirmaba que tal jerarquización traslucía una profunda desconfianza hacia la historia de las ideas, de los discursos, o de las representaciones simbólicas de una sociedad ${ }^{6}$.

A esta réplica agregaría que la desconfianza se extendió hacia la llamada «nueva historia política», a la que el estudio de Myers iluminó en aspectos cruciales. El fino análisis que el autor realiza sobre el conjunto de componentes republicanos - en el que Garavaglia no reparó en su comentario- pone en evidencia la formidable construcción discursiva que

${ }^{6}$ Las intervenciones de ambos autores pueden consultarse en Estudios Sociales, $\mathrm{n}^{\circ} 10 \mathrm{y} \mathrm{n}^{\circ} 11$, 1996. 
representó la idea de una república en constante peligro para establecer la distinción entre amigos y enemigos y configurar las bases de un estado de excepción. Una construcción discursiva sobre la que se montó una también formidable propaganda política, rica en prácticas y rituales, cuya incidencia en la explicación de las adhesiones al rosismo, y a Rosas en particular, no son un detalle menor.

Mirado el fenómeno desde esta perspectiva, si la fortaleza del régimen dependió en gran parte de reconocer la forma de encauzar la movilización popular que había desatado la revolución, también dependió de su capacidad para disciplinar a las elites, no sólo en el plano social y económico sino en el más díscolo espacio político. Como subrayó Halperin (1980), Rosas supo capitalizar las luchas facciosas preexistentes y, extremando al máximo la politización, polarizó a la sociedad tras la causa federal. Vaciado de su contenido original, el federalismo se puso al servicio de un orden que debió enfrentar resistencias de muy diversa índole hasta lograr la domesticación, nunca completa, de la obediencia política que colocaba en su vértice al Restaurador de las Leyes.

Ese vértice nos conduce al tercer núcleo de debate al que me quiero referir: el que atañe a las determinaciones o incidencias del contexto social que hacen posible un rumbo histórico frente a la emergencia de un individuo que le imprime su sello a una época. Un debate que ilustra muy bien el intercambio surgido en torno a la publicación de la más reciente biografía de Juan Manuel de Rosas de Raúl Fradkin y Jorge Gelman (2015), que mereció un agudo comentario de Roy Hora y una respuesta de los autores ${ }^{7}$. En Juan Manuel de Rosas. La construcción de un liderazgo politico, Fradkin y Gelman son claros al fundamentar el enfoque que adoptan. Apoyándose en lo que condensa la cita de Halperin con la que se inicia este parágrafo, al «situar de un nuevo modo su figura en el devenir histórico de la sociedad rioplatense posrevolucionaria», recortan su perspectiva en el propósito de «inscribir al sujeto en su mundo relacional y en sus mutaciones, y reconstruir lo mejor que sea posible esa matriz de relaciones objetivas en la que estuvo inmerso» (Fradkin y Gelman, 2015, p. 21 y 25). Para llevar a cabo este propósito recuperan sus aportes sobre historia rural, social y económica, como asimismo los procedentes de una variada historiografía que se ocupa del período.

En su comentario, Roy Hora destaca las virtudes del libro y, sobre todo, las que van perfilando al personaje antes de ocupar el centro de la

${ }^{7}$ Véase dicho debate en Prohistoria, n 26, 2016, pp. 145-162. 
escena política. En efecto, los capítulos dedicados a bucear en el componente miliciano de su trayectoria pública inicial y el papel que jugó en la construcción de su liderazgo político son los más novedosos e iluminadores. Para el período en el que ocupó la gobernación de Buenos Aires y dominó el espacio de la Confederación, la mirada se desplaza hacia los recursos que ofreció el poder estatal para afianzar un régimen que fue adquiriendo rasgos cada vez más idiosincráticos. Luego de hacer un detallado recorrido por sus principales aportes, Hora deja planteados los límites que encuentra en el enfoque que preside esta biografía -y que adelanta en el título de su comentario, «El factor Rosas»- al no colocar al Restaurador en el centro de sus preocupaciones en tanto actor político, e interpretarlo, ante todo, como un producto de su contexto. Esta limitación se hace particularmente ostensible por tratarse de un personaje público de enorme gravitación, cuya incidencia sobre la vida política y social no reconoce paralelo en el siglo XIX. Para Hora, Rosas no sólo habría demostrado talento para comprender la realidad que le tocó timonear -según enfatizan Fradkin y Gelman- sino también para torcerla de manera nueva y original. Desde este ángulo, el comentario sugiere la fertilidad de explorar en mayor profundidad los cursos de acción y los procesos decisionales que encarnó Rosas y las consecuencias que tuvieron en el derrotero histórico.

En su respuesta, los autores justifican sus opciones metodológicas y señalan que su objetivo fue resaltar la capacidad de su biografiado para comprender los cambios que había traído la revolución, en especial los roles jugados por los sectores populares, tanto rurales como urbanos, y por las divididas y debilitadas elites. Para reafirmar sus planteos sostienen que la crítica formulada en «El factor Rosas» atribuye demasiada importancia a la «voluntad» de un líder político para cambiar el mundo. El gran tema de la voluntad que Fradkin y Gelman introducen en su réplica es un tópico que ha merecido ríos de tinta y cuyo carácter controversial en los campos de la teoría y la filosofía política se traslada a -y resignifica en- el campo historiográfico. No es ésta la ocasión de restituir las conocidas aristas de tales controversias, pero sí es oportuno recuperar algunas de ellas en el marco del debate reseñado, no para agregar nada respecto de las expectativas que despierta la biografía como género, sino para inscribir el problema en el punto de partida de este ensayo: la compleja relación entre Rosas y el rosismo. 


\section{¿Un hombre o un régimen excepcional?}

Patrice Gueniffey (2004), en una contribución titulada «La voluntad en la historia», afirma que hay épocas en que su influencia es relativa y limitada, y otras en las que crece hasta barrer con todos los obstáculos. Ante la pregunta sobre si esta segunda situación debe atribuirse a la aparición de individuos dotados de una «voluntad superior», el autor recorre las diferentes hipótesis asociadas a la fuerza de los contextos, del azar o del carácter excepcional de un individuo. En ese recorrido, que retoma algunas claves interpretativas de François Furet (1990) en El pasado de una ilusión, Gueniffey nos viene a recordar que el surgimiento de «hombres excepcionales» se encuentra muchas veces ligado al estado de excepción, en el sentido amplio del término. En estos casos, la figura del «hombre excepcional se confunde casi con la del dictador; es decir, un individuo al cual las circunstancias excepcionales otorgan poderes extraordinarios, lo que lleva a subordinar el derecho a la voluntad» (p. 7).

La reflexión del autor, que nutrió su ambiciosa empresa como biógrafo de Napoleón Bonaparte (Gueniffey, 2018), se ajusta al caso que nos ocupa, al vincular el tema de la voluntad con la cuestión del estado de excepción. Como sabemos, el carácter dictatorial del régimen rosista ha sido objeto de diversas interpretaciones y las más recientes polemizan sobre el origen y naturaleza de los poderes extraordinarios. El debate suscitado entre Alejandro Agüero y José Carlos Chiaramonte discurre, precisamente, en torno a si el estado de excepción imperante durante la Santa Federación se puede explicar a través de la clave del republicanismo clásico, del gobierno paternal inscripto en la tradición católica hispana, o de la «antigua constitución ${ }^{8}$. El foco de la controversia se ubica aquí en el plano de los referentes culturales y jurídicos de la praxis política; controversia que se inclina más por privilegiar las tradiciones heredadas en las que se habrían nutrido los actores que en reconocer el carácter disruptivo que la revolución trajo consigo en dicha praxis. En cualquier caso, queda abierta la pregunta sobre si en ese estado de excepción es atribuible a Rosas y a su «voluntad»-en términos de decisión y acción consciente en el cambio histórico (Gueniffey, 2004, p. 3)- un carácter performativo. Con este interrogante no apunto a descubrir si estamos ante un «hombre excepcional» dotado de una superior clarividencia, ni a

\footnotetext{
${ }^{8}$ Véase este debate en Nuevo Mundo Mundos Nuevos, 2018 y 2019. DOI: http:// journals.openedition.org/nuevomundo/72785 http://journals.openedition.org/ nuevomundo/75933
} 
las conocidas «circunstancias excepcionales» de las que surgió como hombre público, sino a poner de relieve la originalidad del engranaje político que contribuyó a crear. Y para hacerlo, retomaré los núcleos de debates hasta aquí presentados.

La primera cuestión que merece revisarse proviene de las perspectivas mencionadas en el parágrafo anterior que abordan el fenómeno en una clave social. Casi todas ellas destacan, con diferentes matices y énfasis, la necesidad que tuvo Rosas de revalidar constantemente su liderazgo a través de prácticas de negociación con variados grupos y actores, ante reclamos, reivindicaciones y formas de resistencia frente al disciplinamiento estatal. El problema que observo en estos enfoques reside en la traducción interpretativa de esas formas segmentadas de negociación a la esfera política. Es decir, en la tendencia a subsumir o diluir la naturaleza específica del vínculo político en términos del grado de «agencia» o «pasividad» de los actores sociales frente a los agentes estatales. Desde este ángulo, si bien es muy cierto que Rosas negociaba reclamos y reivindicaciones puntuales de diversa procedencia, según muestran los estudios en esta dirección a partir de una abundante documentación de archivo, es preciso recordar que no negociaba con nadie, ni siquiera con su séquito más cercano, las llaves maestras con las que disciplinó las adhesiones políticas a partir de 1835 . A saber, la lista única de candidatos a las elecciones que él confeccionaba personalmente, el control logístico de los comicios, y la suma del poder público que hizo derivar a una ratificación directa del pueblo. Al mismo tiempo, hay que recordar también que si hubo espacios de resistencia y agencia de los sectores subalternos y de abierta rebelión por parte de sectores poderosos, como fue el caso de los Libres del Sur en 1839, no se registran gestos de resistencia al aparato unanimista impuesto desde el segundo gobierno rosista. A nadie se le ocurría armar una lista de candidatos alternativa ni votar en disidencia en las mesas electorales.

La segunda cuestión a discutir atañe a las siempre debatidas líneas de continuidad y cambio de un fenómeno histórico. Creo que para tener una imagen más completa y ajustada del rosismo sería fértil reubicar el papel de la singular arquitectura política que vino a romper de manera abrupta con el pasado republicano posrevolucionario como asimismo con las antiguas culturas jurídicas del orden colonial (Sabato y Ternavasio, 2020). Sabemos que las razones del éxito de esa arquitectura no pueden reducirse al miedo: hay un extendido consenso historiográfico que reconoce que la adhesión a la causa federal del rosismo no deriva 
solamente de la fuerte dosis de coacción que el régimen aplicó. Pero la explicación tampoco se agota en los entramados capilares asimétricos que $\rightarrow$ al ras del suelo»- componen y articulan a los actores sociales y agentes estatales en los espacios locales, ni en las inercias de viejas tradiciones. ¿Cómo interpretar, entonces, lo que por mucho tiempo fue calificado como una suerte de farsa o simulacro del poder sin perder de vista lo que ese gesto encerraba en términos de invención política?

He aquí donde emerge la tercera cuestión: la «voluntad» del Restaurador de las Leyes. Su importancia no reside en la vocación unanimista que lo obsesionó desde el comienzo de su gestión -en línea con el clima de época que aspiraba al ideal de unidad del cuerpo político- sino en su decisión de traducirla en una potente maquinaria política. El carácter performativo de esa fábrica de discursos, imágenes, rituales y slogans que producía adhesiones a la causa federal rosista, terminó de cristalizarse con la práctica plebiscitaria. Su rol primordial consistió en escenificar la visibilidad del consenso e invisibilizar la potencial disidencia política. El andamiaje destinado a homogeneizar en un todo indistinguible la unanimidad de la voluntad general era, a la vez, el mecanismo idóneo para singularizar las relaciones de mando y obediencia. Por un lado, singularizaba hasta el grotesco la figura de Rosas, cuyo nombre y retrato invadió la vida pública y privada; por el otro, individualizaba los apoyos como asimismo las abstenciones, vistas siempre bajo un manto de sospecha (Ternavasio, 2003).

Es un tema aún por explorar en qué repertorios buceó el rosismo para convertir al plebiscito en parte fundamental de su arquitectura de poder. Es bien conocido que el mecanismo de las consultas populares fue utilizado en ciertas ocasiones en los procesos revolucionarios hispanoamericanos con el objeto de obtener el aval para la aprobación de reglamentos o decisiones adoptadas por los líderes políticos. Así lo hizo, entre otros, José Gervasio Artigas, quien además lo utilizó para ratificar su legitimidad como Protector (Frega, 2007). En estos casos, las consultas se solapaban con el antiguo derecho de petición y navegaban entre el ejercicio directo de la soberanía popular y la adopción de regímenes representativos para regular la relación entre gobernantes y gobernados. Pero el régimen rosista alcanzó un grado de sofisticación mucho más elaborado de lo que estos antecedentes mostraban, al coagular dichas modalidades en un sistema que le permitía afirmar, como lo hizo después del primer plebisicito de 1835, que el resultado «ha sido la expresión de la voluntad general que aclama al Sr. General Rosas como ciuda- 
dano designado para salvar la provincia de los graves peligros que amagan» ${ }^{9}$.

¿Podríamos rastrear allí una clave napoleónica que recuperaba al primer Bonaparte y la instrumentación de plebiscitos para respaldar los sumos poderes que asumió como cónsul vitalicio y luego como emperador? La leyenda del «Cromwell de la Revolución»-como gustaba llamarlo Stendhal- estaba ampliamente difundida, y una pista posible es Pedro de Angelis, figura central en la elaboración del discurso público de Rosas. De Angelis había sido no sólo testigo sino participante activo de las redes bonapartistas en el Reino de Nápoles de donde era oriundo. Allí se desempeñó como ayo de los hijos de José Bonaparte y luego de Murat, cuando ambos reinaron durante la expansión del imperio napoleónico en el sur de Italia. Si damos crédito al testimonio de José Rivera Indarte, uno de los opositores a Rosas más emblemáticos, la pista no es descabellada. Rivera Indarte relataba lo siguiente:

En las vacilaciones de Rosas para apoderarse en ese año de 1834 del poder absoluto, Angelis lo socorrió con su erudición, indicándole «que imitase a Napoleón e hiciese confirmar por el pueblo la elección de la Sala». Esta farsa plagiada agradó mucho a Rosas, y permitió a la Encarnación y a su hija la manuela, que recibiesen a Angelis con agrado siempre que se les presentase ${ }^{10}$.

No sabemos si fue el publicista napolitano el que orientó al Restaurador a poner en práctica la «farsa plagiada», aunque el testimonio citado es muy verosimil. La clave napoleónica podría rastrearse, además, en otros aspectos vinculados a los rituales y usos de la iconografía rosista, o al común desprecio que ambos personajes demostraron frente a «la política» entendida como espacio de deliberación en el foro legislativo o en la prensa periódica. Con esta clave no aspiro a reponer los viejos debates en torno a las categorías de bonapartismo o cesarismo para interpretar a Rosas, sobre las que Raúl Fradkin (2014) realiza un oportuno examen, sino a marcar que la inauguración de un repertorio republicano de tipo plebiscitario nos invita a reflexionar más allá del plano meramente descriptivo y a revisar sus repercusiones y proyecciones después del período que se cerró con Caseros.

\footnotetext{
${ }^{9}$ La Gaceta Mercantil, Buenos Aires, 30 de Marzo de 1835.

${ }^{10}$ José Rivera Indarte, Rosas y sus opositores, Buenos Aires, W.M. Jackson, s/f.
} 
Las repercusiones iniciales las vimos en el juicio a Rosas y se observan en la flamante constitución de 1853 que estableció en el artículo 29 -retomando el fallido proyecto constitucional de 1833- que «El Congreso no puede conceder al Ejecutivo nacional, ni las Legislaturas provinciales a los gobernadores de provincia, facultades extraordinarias, ni la suma del poder público». Y, como sabemos, las proyecciones se extenderán a coyunturas posteriores, cuando reaparezca el fantasma al que podía conducir el ejercicio de la soberanía popular si se disponía a dotar de fuertes poderes a una autoridad unipersonal abierta a encarnar la representación del cuerpo político como un todo. Sobre ese fantasma advirtió, por ejemplo, José Nicolás Matienzo (1915) en vísperas de las primeras elecciones presidenciales bajo la reforma electoral sancionada en 1912: «Un plebiscito dio a Luis Napoleón el imperio en Francia, como poco antes un plebiscito había dado la suma del poder público a Rosas en la provincia de Buenos Aires» (p. 447). Con el triunfo de Hipólito Irigoyen, los grupos que se vieron desplazados del poder creían confirmar aquella advertencia y recurrieron, una y otra vez, a la comparación entre el estilo de liderazgo del flamante presidente y el Restaurador de la Leyes.

No será ésta la primera ni la última ocasión en que se lo compare a Rosas con un líder político del siglo XX. La emergencia del peronismo volverá a recrear las analogías, y en este punto, las comparaciones nos regresan al controvertido tema de la voluntad en la construcción de un liderazgo político. El «factor Rosas» al que aludía Roy Hora en el comentario citado no puede sino evocar el «factor Perón» que propone Juan Carlos Torre (2014) en un artículo en el que comienza señalando el riesgo de «destacar en demasía el papel del individuo en la determinación de los hechos de la historia y dejar en un segundo plano la importancia del marco social y político dentro del que tuvieron lugar los hechos». A continuación, sin embargo, admite que lo que marca la diferencia en determinadas coyunturas es la posición de preeminencia que ocupan determinadas personalidades políticas «para modelar la arcilla humana y la trama de acontecimientos». La responsabilidad histórica, nos dice el autor, «no está democráticamente distribuida» (p. 299).

\section{La representación-encarnación}

En un reciente libro, titulado El siglo del populismo, Pierre Rosanvallon (2020) se propone trazar una historia, una teoría y una crítica para 
reflexionar sobre el fenómeno que «revoluciona la política del siglo XXI» a escala global (p. 13). No es mi propósito discutir aquí la cuestión populista ni trazar ligeras genealogías, sino llamar la atención sobre el punto de arranque histórico que adopta el autor para su análisis. Ese punto es Napoleón III, a quien le atribuye haber retomado «el dispositivo montado por su tío»-el «plebiscito bonapartista»- pero «teorizándolo y otorgándole a su vez todo su alcance». Dicho dispositivo no consistió en «una simple consulta al pueblo» sino en un principio de «representación-encarnación» del «pueblo-Uno» que reducía su participación a la manifestación de una masa unánime (p. 104). En ese momento iniciático, el autor detecta algunos elementos que serán recurrentes hasta el presente, tomando ejemplos de diversas latitudes y contrapuestos signos ideológicos: la polarización política, la desconfianza a la libre deliberación o el rechazo a la intervención de cuerpos intermedios que interfieran entre el líder y el pueblo que viene a encarnar. Pero hay dos cuestiones que Rosanvallon destaca y en las que me interesa detenerme brevemente por estar en el centro de mi argumento sobre las lecturas y escrituras del rosismo.

La primera remite a la potencia que asumió la personificación del poder y que el autor ilustra a través de Madame de Staël (1818), en la obra citada al comienzo, quien supo definirla sencillamente al referirse al ascenso del primer Napoleón cuando regresó de Egipto: «Era la primera vez, después de la Revolución, que se escuchaba un nombre propio en todas las bocas» (p. 204). Para la célebre autora, el dilema era que la personificación del poder surgía del seno de la soberanía popular al consagrar «a un hombre elegido por el pueblo, que quiso poner su yo gigantesco en el lugar de la especie humana» (p. 237). Aunque Rosas tuvo sus propios detractores, los dichos de Madame de Staël aplicarían perfectamente al caso.

La segunda cuestión remite al plebiscito (o «referéndum», término que se impuso a finales del siglo XIX) como problema teórico y a la vez histórico. Rosanvallon afirma que su exploración nunca fue llevada a cabo de manera sistemática y requiere trabajar en profundidad sobre sus puntos ciegos. A saber: la disolución de la responsabilidad política, la confusión entre las nociones de decisión y voluntad, la sacralización del expediente técnico de la mayoría con su consiguiente dimensión de irreversibilidad, y el silencio respecto de la traducción en normas de la opción ganadora (Rosanvallon, 2020, pp. 183-184). Por cierto que el autor no menciona la experiencia rosista en su recorrido histórico -tal vez por 
«sus brutales simplificaciones políticas»-mientras que el peronismo ocupa varias páginas. No obstante, los puntos ciegos que señala para indagar las consecuencias y proyecciones de los ensayos políticos plebiscitarios en el largo plazo ya estaban presentes entre los encargados de enjuiciar a Rosas en la década de 1850, mientras el «sobrino del tío» se erigía en emperador y Marx escribía su diatriba en El Dieciocho Brumario.

Como viene ocurriendo desde hace más de un siglo y medio, el lugar atribuido a Rosas en las narrativas históricas y en la tradición republicana sigue siendo un tema de debate en el que se entrelazan historia, memoria y política. Y tal vez la gran fascinación que despierta el personaje entre muchos especialistas del período - $\mathrm{O}$ al menos para quien escribe estas líneas- reside en el desafío de tratar de entender ese lugar en la construcción de la original arquitectura política rosista. Un desafío que implica restituir tanto sus condiciones de emergencia en el contexto de una sociedad sometida a la constante amenaza de disolución de todos sus lazos, como «las obsesiones de un Rosas» que, según nos recuerda Halperin, consideraba que ante ese inminente peligro era su «solitaria clarividencia» la que le fijaba el deber y le otorgaba el derecho «de imponer su enérgica guía». Desde esa convicción -nos dice el autor- «la victoria del discurso clásico-republicano es la del instrumento que permite hacer de una visión -personal hasta el delirio- en que una entera sociedad se encamina ciegamente a su aniquilación irrevocable, el fundamento de una duradera fe colectiva» (Tulio Halperin Donghi, 2005, p. 90).

En la confluencia de esa fe colectiva y de un liderazgo personal anclado en la polarización extrema del conflicto político es posible identificar los rasgos de un repertorio que, si en jerga contemporánea asumiría de manera intuitiva la dimensión agonal de la política, para Sarmiento y muchos de sus contemporáneos se cifró en clave de enigma. La expectativa del autor de Facundo de que el «misterio» sería descifrado por «me-jores y más imparciales estudios que los que hasta hoy hemos hecho» continúa en la agenda de los historiadores. Una agenda que, como vimos, sigue abierta al diálogo y a las controversias.

\section{Bibliografía citada}

Bari, C. (2020). El momento cismático. El debate politico en la undécima legislatura porteña (1833). Tesis de Maestría en Historia, Buenos Aires, Argentina: Universidad Torcuato Di Tella. 
Eujanian, A. (2015). El pasado en el péndulo de la politica. Rosas, la provincia y la nación en el debate politico de Buenos Aires, 1852-1861. Bernal, Argentina: Universidad Nacional de Quilmes.

Fradkin, R. (2014). Dictaduras temporales, bonapartismos y caudillismos. En De Francesco, A., Migliori, L. M. y Nocera, R. (Coords.), Entre el Mediterráneo y el Atlántico. Circulaciones, conexiones y miradas, 1756-1867 (pp. 393-420). Santiago, Chile: Fondo de Cultura Económica.

Fradkin, R. y Gelman, J. (2015). Juan Mamuel de Rosas. La construcción de un liderazgo politico. Buenos Aires, Argentina: Edhasa.

Franco, M. (2018). La última dictadura argentina en el centro de los debates y las tensiones historiográficas recientes, Tempo e Argumento, $\mathrm{n}^{\circ} 23$, pp. 138166.

Frega, A. (2007). Pueblos y soberanía en la revolución artiguista. La región de Santo Domingo Soriano desde fines de la colonia a la ocupación portuguesa, Montevideo, Uruguay: Ediciones de la Banda Oriental.

Furet, F. (1990). El pasado de una ilusión. México DF, México: Fondo de Cultura Económica.

González Bernaldo, P. (2001). Civilidad y politica en los orígenes de la Nación Argentina. Las sociabilidades en Buenos Aires, 1829-1862. Buenos Aires, Argentina: Fondo de Cultura Económica.

Gueniffey, P. (2004). La voluntad en la Historia, Istor, n 17, pp. 3-20.

Gueniffey, P. (2018). Bonaparte; 1769-1802. México DF, México: Fondo de Cultura Económica.

Halperin Donghi, T. (1972). Revolución y guerra. Formación de una elite dirigente en la Argentina criolla. Buenos Aires, Argentina: Siglo XXI.

Halperin Donghi, T. (1980). Historia Argentina. De la revolución de independencia a la confederación rosista. Buenos Aires, Argentina: Paidós.

Halperin Donghi, T. (2005). Republicanismo clásico y discurso político rosista, en Halperin Donghi, T., El revisionismo histórico argentino como visión decadentista de la bistoria nacional, pp. 75-90. Buenos Aires, Argentina: Siglo XXI.

Marx, C. (1973). El Dieciocho Brumario de Luis Bonaparte. Buenos Aires, Argentina: Anteo. 
Matienzo, J. N. (1915). El gobierno de la opinión pública, Revista Argentina de Ciencias Politicas, $\mathrm{n}^{\circ}$ 59, pp. 433-450.

Munilla Lacasa, M. L. (2013). Celebrar y gobernar. Un estudio de las fiestas cinicas en Buenos Aires, 1810-1835. Buenos Aires, Argentina: Miño y Dávila.

Myers, J. (1995). Orden y Virtud. El discurso republicano en el régimen rosista. Bernal, Argentina: Universidad Nacional de Quilmes.

Rosanvallon, P. (2020). El siglo del populismo. Historia, teoria, crítica. Buenos Aires, Argentina: Manantial.

Sabato, H. y Ternavasio, M. (coords.). (2020). Variaciones de la república. La politica en la Argentina del siglo XIX. Rosario, Argentina: Prohistoria.

Salvatore, R. (1998). Fiestas federales: representaciones de la república en el Buenos Aires rosista, Entrepasados, $\mathrm{n}^{\circ}$ 11, pp. 45-68.

Salvatore, R (2003). Wandering Paysanos. State Order and Subaltern Experience in Buenos Aires during the Rosas Era. Durham and London, Estados Unidos: Duke University Press. Traducción española (2018). Paisanos itinerantes. Orden estatal y experiencia subalterna en Buenos Aires durante la era de Rosas. Buenos Aires, Argentina: Prometeo.

Staël, M. [1818], (1838). Considérations sur les principaux événements de la Révolution française, Euvres posthumes. París, Francia: FirminDidot.

Stendhal (2007). Vida de Napoleón. Barcelona, España: Verticales de Bolsillo.

Ternavasio, M. (2002). La revolución del voto. Politica y elecciones en Buenos Aires, 1810-1852. Buenos Aires, Argentina: Siglo XXI.

Ternavasio, M. (2003). La visibilidad del consenso. Representaciones en torno al sufragio en la primera mitad del siglo XIX. En Sábato, H. y Lettieri, A. (Comps.), La vida politica en la Argentina del siglo XIX. Armas votos y voces (pp. 57-74). Buenos Aires, Argentina: Fondo de Cultura Económica.

Torre, J. C. (2014). A propósito del Factor Perón, Estudios Sociales, $n^{\circ} 46$, pp. 299-310. 